\title{
Reliability of fine needle aspiration biopsy in large thyroid nodules
}

\author{
Osman Bozbıyık', Șafak Öztürk', Mutlu Ünver', Varlık Erol'1, Ümit Bayol², Cengiz Aydın
}

\begin{tabular}{|c|c|}
\hline \multirow[t]{5}{*}{ ABSTRACT } & $\begin{array}{l}\text { Objective: Fine needle aspiration biopsy provides one of the most important data that determines the treatment } \\
\text { algorithm of thyroid nodules. Nevertheless, the reliability of fine needle aspiration biopsy is controversial in large } \\
\text { nodules. The aim of this study was to evaluate the adequacy of fine needle aspiration biopsy in thyroid nodules } \\
\text { that are four } \mathrm{cm} \text { or greater. }\end{array}$ \\
\hline & $\begin{array}{l}\text { Material and Methods: We retrospectively examined } 219 \text { patients files who underwent thyroidectomy for thyroid } \\
\text { nodules that were greater than four centimeter between May } 2007 \text { and December } 2012 \text {. Seventy-four patients with } \\
\text { hyperthyroidism, and } 18 \text { patients without preoperative fine needle aspiration cytology were excluded from the } \\
\text { study. Histopathologic results after thyroidectomy were compared with preoperative cytology results, and sensitivity } \\
\text { and specificity rates were calculated. }\end{array}$ \\
\hline & $\begin{array}{l}\text { Results: False-negativity, sensitivity and specificity rates of fine needle aspiration biopsy of thyroid nodules were } \\
\text { found to be } 9.7 \%, 55.5 \% \text {, and } 85 \% \text {, respectively. Within any nodule of the } 127 \text { patients, } 28(22.0 \%) \text { had thyroid cancer. } \\
\text { However, when only nodules of at least } 4 \mathrm{~cm} \text { were evaluated, thyroid cancer was detected in } 22(17.3 \%) \text { patients. }\end{array}$ \\
\hline & $\begin{array}{l}\text { Conclusion: In this study, fine needle aspiration biopsy of large thyroid nodules was found to have a high false- } \\
\text { negativity rate. The limitations of fine-needle aspiration biopsy should be taken into consideration in treatment } \\
\text { planning of thyroid nodules larger than four centimeters. }\end{array}$ \\
\hline & Keywords: Fine needle aspiration biopsy, thyroidectomy, thyroid cancer, thyroid nodule \\
\hline
\end{tabular}

Cite this paper as: Bozbiyık 0, Ozztürk ş, Ünver $M$, Erol V, Bayol Ü, Aydın C. Reliability of fine needle aspiration biopsy in large thyroid nodules. Turk J Surg 2017; 33(1): 10-13.

This study was presented at the $6^{\text {th }}$ National Endocrine Surgery Congress, 23-25 April 2013, Antalya, Turkey.

'Clinic of General Surgery, İzmir Tepecik Training and Research Hospital, İzmir, Turkey ${ }^{2}$ Clinic of Pathology, Izmir Tepecik Training and Research Hospital, İzmir, Turkey

Address for Correspondence Osman Bozbiyık e-mail: bozbiyiko@gmail.com

Received: 14.08.2015 Accepted: 28.11.2015

(C) Copyright 2017 by Turkish Surgical Association
Available online at www.turkjsurg.com

\section{INTRODUCTION}

Fine needle aspiration biopsy (FNAB) is a cost-efficient method that should be primarily preferred and gives the most accurate results in suspicious thyroid nodules detected by ultrasound (1). With the use of fine needle aspiration biopsy, the diagnosis of thyroid cancer can be made with a high sensitivity and specificity, and its routine use prevents many unnecessary surgical operations (2-4). Although FNAB is the gold standard test, it does have some limitations $(5,6)$. Its reliability in thyroid nodules larger than $4 \mathrm{~cm}$ in size is still controversial. Diagnostic lobectomy/thyroidectomy has been recommended because of a high rate of false negativity of FNAB in large thyroid nodules in some studies, while many studies have reported that FNAB can be used with reliability in large nodules as well (6-15). In addition, there are publications showing that the prevalence of thyroid cancer increases as the nodule diameter increases $(7,9,10)$. In this study, we aimed to determine the reliability of FNAB in thyroid nodules larger than $4 \mathrm{~cm}$ in size.

\section{MATERIAL AND METHODS}

The data of 1563 patients who underwent thyroidectomy between May 1, 2007 and December 31, 2012 were examined retrospectively. The data of 219 patients who had a thyroid nodule larger than $4 \mathrm{~cm}$ in size according to pathology reports were examined. The demographic properties of the patients, preoperative TSH levels, history of drug use, preoperative FNAB results, numbers of nodule and definite pathology results were examined. 74 patients whose THS levels were below the normal limit or who had a history of antithyroid drug usage were excluded from the study. In addition, 18 patients who did not undergo FNAB before surgery were also excluded from the study. A total of 127 patients were included in the study.

In our clinic, thyroidectomy is performed in all patients with a thyroid nodule larger than $4 \mathrm{~cm}$ in size. Therefore, our sample represents all patients who have a thyroid nodule larger than $4 \mathrm{~cm}$ in size. The results of FNAB performed preoperatively were grouped as: benign, follicular lesion, follicular neoplasia, suspicious in terms of papillary cancer, malignant and insufficient for diagnosis. The results of histopathologic examination were grouped as: nodular goiter, follicular adenoma and malignant. The preoperative FNAB results and postoperative histopathologic examination results were compared. FNABs obtained from the nodules other than large nodules were not included in the study. The false negativity, sensitivity and specificity rates for FNAB were evaluated. The malignancies found in the nodules other than the ones with a size larger than $4 \mathrm{~cm}$ were not included in the calculations of false negativity, sen- 
sitivity and specificity, because they were beyond the scope of this study; these malignancies were specified separately.

This research was conducted according to the principles of the World Medical Association Declaration of Helsinki “Ethical Principles for Medical Research Involving Human Subjects".

\section{Statistical Analysis}

The data were recorded in the software prepared with Microsoft Excel v: 12.0 (Microsoft Corporation, Santa Rosa, CA, USA) and the mean and percentage values were calculated. No additional statistic methods was used.

\section{RESULTS}

The mean age of the 127 patients included in the study was 47.8 years (18-75 years). 89 (70.1\%) of the patients were female and $38(29.9 \%)$ were male. The mean nodule diameter was found to be $49.0 \mathrm{~mm}$, the smallest and largest nodule size was $40 \mathrm{~mm}$ and $90 \mathrm{~mm}$, respectively. 28 (22.0\%) of the patients had a solitary thyroid nodule while 99 (77.9\%) had multiple thyroid nodules. Cytologic evaluation of the patients who underwent fine needle aspiration biopsy revealed benign cytology in 82 patients, suspicious cytology in terms of papillary thyroid cancer in 12 patients, cytology compatible with follicular lesion/neoplasia in 8 patients, malignant cytology in 3 patients, and insufficient cytology for a diagnosis in 22 patients. When only those nodules larger than $4 \mathrm{~cm}$ in size were included in postoperative histopathologic evaluation, nodular goiter was detected in 95 patients, follicular adenoma in 10 patients, papillary cancer in 14 patients and follicular cancer in 8 patients. A papillary cancer focus was found in 6 of 95 patients whose nodules larger than $4 \mathrm{~cm}$ in size was found to be benign. Thus, thyroid cancer was detected in 28 (22.0\%) out of a total of 127 patients, whereas thyroid cancer was found in 22 patients (17.3\%) when only those nodules larger than $4 \mathrm{~cm}$ in size were considered.

When the histopathologic results of 82 patients whose fine needle aspiration biopsy was found to be benign were examined, it was observed that 74 patients had nodular goiter, 3 patients had follicular thyroid cancer, and 5 patients had papillary thyroid cancer. Definite histopathologic examination of 8 patients whose fine needle aspiration cytology was compatible with follicular lesion/neoplasia revealed follicular adenoma in 6 patients and follicular thyroid cancer in 2 patients. When the histopathologic results of 12 patients whose preoperative cytologic examination was considered to be suspicious in terms of papillary cancer were examined, benign nodule was found in 7 patients, follicular thyroid cancer was found in 1 patient and papillary thyroid cancer was found in 4 patients (Table 1). Thus, the malignancy rate was found to be $41.6 \%$ in patients with suspicious cytology. Papillary thyroid cancer was found on histopathologic examination in all three patients whose preoperative FNAB was considered to be malign. On histopathologic examination of 21 patients whose preoperative FNAB was insufficient for making a diagnosis, nodular goiter was detected in 15 patients, follicular adenoma in 3 patients, follicular cancer in 2 patients and papillary cancer in 1 patient. When these results were evaluated, fine needle biopsy in thyroid nodules larger than $4 \mathrm{~cm}$ in size was found to have a false negativity rate of $9.7 \%$, a specificity rate of $85.0 \%$ and a sensitivity rate of $55.5 \%$.
Table 1. Comparison of preoperative cytology findings with postoperative histopathology results

\begin{tabular}{|l|c|c|}
\hline Fine needle aspiration cytology & \multicolumn{2}{c|}{ Histopathology } \\
\hline Benign (n: 82$)$ & $\mathbf{n}$ & Result \\
\hline & 34 & Nodular goiter \\
\hline Follicular lesion/neoplasia $(\mathrm{n}: 8)$ & 5 & Papillary carcinoma \\
\hline & 6 & Follicular adenoma \\
\hline Suspicious cytology $(\mathrm{n}: 12)$ & 2 & Follicular carcinoma \\
\hline & 7 & Nodular goiter \\
\hline & 1 & Follicular carcinoma \\
\hline Malignant $(\mathrm{n}: 3)$ & 4 & Papillary carcinoma \\
\hline
\end{tabular}

\section{DISCUSSION}

Fine needle aspiration biopsy (FNAB) is a cost-efficient method that should be primarily preferred and gives the most accurate results in suspicious thyroid nodules detected by ultrasound (1). FNAB has been shown to be feasible in the assessment of thyroid nodules with a sensitivity of $65-98 \%$, a specificity of $72-100 \%$, and a false negativity rate below $5 \%$ (2). Many unnecessary thyroidectomies can be prevented with the routine use of FNAB. Several factors including sampling error, fixation method, presence of non-homogenous nodule and the effect of the interpreter cyto-pathologist affect the success of FNAB (3-5). In addition, the adequacy of fine needle aspiration biopsy in the assessment of thyroid nodules larger than $4 \mathrm{~cm}$ in size is still controversial.

High false negativity rates lead to treatment delay and poor prognosis. In this study, we found that FNAB had a false negativity rate of $9.7 \%$, a sensitivity of $55.5 \%$ and a specificity of $85 \%$ in thyroid nodules larger than $4 \mathrm{~cm}$ in size. Yeh et al. (16) reported the delay in treatment in thyroid cancers that could not be detected by FNAB as 28.2 months, and vascular invasion and capsule invasion were found at a higher rate in these patients. Thus, the error rate of FNAB is regarded as a factor affecting prognosis. In the literature, some publications have reported the false negativity rate of FNAB to be as low as $0.7 \%$ in large thyroid nodules while several other studies have reported this rate to be $17 \%$ (Table 2) (6-15).

In a leading study in this area, Meko et al. (6) reported that the rate of false negativity was $0 \%$ in solid nodules smaller than 3 $\mathrm{cm}$ while it was $17 \%$ in nodules larger than $3 \mathrm{~cm}$. They found that the false negativity rate increased to $30 \%$ if nodules larger than $3 \mathrm{~cm}$ had both cystic and solid components. Based on these results, they recommended routine lobectomy for all large nodules. Mac Coy et al. (7) found the prevalence of cancer to be $19.3 \%$ in thyroid nodules larger than $4 \mathrm{~cm}$ and the false negativity rate of FNAB to be $13 \%$ in a study including 223 patients, and recommended diagnostic lobectomy for nodules larger than 4 $\mathrm{cm}$. These results are compatible with our data. In contrast, some studies have reported that FNAB can be used with a success rate of $0.7-6.2 \%$ in large thyroid nodules. In these studies, it has been stated that FNAB can be reliably applied in large thyroid nodules as well, and that nodule size alone should not be an indication for lobectomy/thyroidectomy $(8,10,11)$. 
Table 2. Published series on reliability of fine needle aspiration biopsy for large thyroid nodules

\begin{tabular}{|c|c|c|c|c|c|c|c|}
\hline & $\begin{array}{c}\text { Nodule } \\
\text { diameter }(\mathrm{cm})\end{array}$ & $\begin{array}{l}\text { Patient } \\
\text { number }\end{array}$ & $\begin{array}{l}\text { Malignancy } \\
\text { rate (\%) }\end{array}$ & $\begin{array}{c}\text { False } \\
\text { negativity (\%) }\end{array}$ & $\begin{array}{l}\text { Sensitivity/ } \\
\text { specifity (\%) }\end{array}$ & $\begin{array}{l}\text { FNAB } \\
\text { method }\end{array}$ & $\begin{array}{l}\text { Suggests routine } \\
\text { lobectomy }\end{array}$ \\
\hline Meko et al. (6) & $>3$ & 52 & 21 & 17 & & Manual & YES \\
\hline MacCoy et al. (7) & $>4$ & 223 & 19.3 & 13 & & US & YES \\
\hline Porterfield et al. (8) & $>3$ & $742(145)$ & & 0.7 & & US & NO \\
\hline Pinchott S.N. et al. (9) & $>4$ & 155 & 13.5 & 6 & & Manual and US & YES \\
\hline Kuru et al. (10) & $>4$ & 148 & 24 & 4.3 & $88 / 86$ & US & NO \\
\hline Yoon YH et al. (11) & $>3$ & $661(206)$ & 11.2 & 2 & $96.7 / 85.5$ & US & NO \\
\hline Raj MD (12) & $>4$ & 223 & 7.2 & 6.2 & $93.8 / 62.2$ & US & NO \\
\hline Albuja-cruz et al. (13) & $>4$ & 212 & 35 & 15 & $35 / 99$ & US & NO \\
\hline Wharry et al. (15) & $>4$ & 361 & 21.7 & 10.4 & & & YES \\
\hline This study & $>4$ & 127 & 17.3 & 9.7 & $55.5 / 85$ & Manual and US & YES \\
\hline
\end{tabular}

In the study conducted by Porterfield et al. (8), which has the best results in the literature, the false negativity rate of FNAB was reported to be $0.7 \%$ in 696 patients who had nodules larger than $3 \mathrm{~cm}$ in size. However, surgery was performed and definite histopathologic result could be obtained in only 145 of these patients. 550 of the remaining 551 were considered benign based on clinical follow-up. Definite histopathology was evaluated only in $20 \%$ of the patients and the false negativity rate of FNAB was found to be $0.7 \%$. Yoon et al. (11) reported the false negativity rate of FNAB to be $2 \%$ in nodules larger than $3 \mathrm{~cm}$ in size. In this study, surgery was performed only in 206 of 661 patients and all other patients were considered as benign as a result of clinical follow-up. Absence of definite histopathologic results in the majority of patients is a significant limiting factor in these two studies which showed that FNAB could be applied with success in large thyroid nodules. One of the difficulties encountered while calculating false negativity rates is the absence of a definite histopathologic diagnosis in many cases because of lack of surgery in patients with benign cytology. This affects false negativity rates. In our series in which we reported the false negativity rate to be $9.7 \%$, histopathologic results were present in all patients. Kuru et al. (10) presented one of the most successful series in the literature with a high rate of histopathologic confirmation. They found the false negativity rate of FNAB to be $1.3 \%$ for thyroid nodules smaller than $4 \mathrm{~cm}$ in size and $4.3 \%$ for thyroid nodules larger than $4 \mathrm{~cm}$ in size. In their series, a definite histopathologic diagnosis was present in $86 \%$ of the subjects. However, all current series do not report such levels of success rates. Similar to our series, Wharry et al. (15) found the false negativity rate to be $10.4 \%$ in nodules larger than $4 \mathrm{~cm}$ in size in their series which consisted of 361 patients. In a current study from our country, Agcaoglu et al. (14) found the false negativity rate to be $11 \%$ in large thyroid nodules.

One of the mainstays of the authors who recommend routine lobectomy/thyroidectomy in large thyroid nodules is the increased possibility of malignancy in addition to the high false positivity rate of FNAB (7). The rate of cancer in large thyroid nodules has been reported to be $7.2-35 \%$ (6-15). In our series, the rate of thyroid cancer was $17.3 \%$ when only nodules larger than $4 \mathrm{~cm}$ in size were considered. As the diameter of the thyroid nodule increases, the prevalence of cancer increases $(7,9,10)$.
When the nodule is non-homogenous and contains cystic and solid components, the diagnostic sufficiency of FNAB decreases $(6,17)$. Sampling only the cystic content decreases the chance of success especially in nodules with cystic and solid components. In other words, the success rate is higher when FNAB is performed under ultrasound guidance $(12,17,18)$. In our series, the fact that biopsy of palpable lesions was performed without ultrasound guidance might be one of the reasons which increased the false negativity rate. Agcaoglu et al. (14) found that lack of accompaniment of a cytopathologist in the FNAB procedure increased the false negativity rate. In our study, cytopathologists did not accompany in any FNAB procedure. This may be another factor which increased the false negativity rate.

\section{CONCLUSION}

The data in the literature related to the reliability of FNAB in nodules larger than $4 \mathrm{~cm}$ in size are controversial. The limitations of FNAB should be taken into consideration when making treatment decisions in nodules larger than $4 \mathrm{~cm}$ in size. Well-planned prospective studies including factors such as technical causes, presence of non-homogeneous nodules, and cytopathologist effect are needed in this area.

Ethics Committee Approval: Authors declared that the research was conducted according to the principles of the World Medical Association Declaration of Helsinki "Ethical Principles for Medical Research Involving Human Subjects", (amended in October 2013).

Informed Consent: Informed consent was not received due to the retrospective nature of the study.

Peer-review: Externally peer-reviewed.

Author Contributions: Concept - O.B., C.A., U.B.; Design - C.A., U.B.; Supervision - C.A., U.B.; Resource - M.U., V.E.; Materials - S.O., M.U.; Data Collection and/or Processing - O.B., S.O., V.E.; Analysis and/or Interpretation - S.O., V.E.; Literature Search - O.B., M.U.; Writing Manuscript O.B.; Critical Reviews - C.A.

Conflict of Interest: No conflict of interest was declared by the authors.

Financial Disclosure: The authors declared that this study has received no financial support. 


\section{REFERENCES}

1. American Thyroid Association (ATA) Guidelines Taskforce on Thyroid Nodules and Differentiated Thyroid Cancer, Cooper DS, Doherty GM, Haugen BR, Kloos RT, Lee SL, et al. Revised American Thyroid Association management guidelines for patients with thyroid nodules and differentiated thyroid cancer. Thyroid 2009; 19: 1167-1214. [CrossRef]

2. Gharib H, Goellner JR, Johnson DA. Fine-needle aspiration cytology of the thyroid: a 12-year experience with 11,000 biopsies. Clin Lab Med 1993; 13: 699-709.

3. Hambleton C, Kandil E. Appropriate and accurate diagnosis of thyroid nodules: a review of thyroid fine-needle aspiration Int J Clin Exp Med 2013; 6: 413-422.

4. Ogilvie JB, Piatigorsky EJ, Clark OH. Current status of fine needle aspiration for thyroid nodules. Adv Surg 2006; 40: 223-238. [CrossRef]

5. Çahalov M, Makay O, Içöz G, Akyıldız M, Yılmaz M. What should be done in thyroid nodules less than two centimeters, ultrasonographically suspicious and cytologically benign? Ulusal Cer Derg 2013; 29: 167-170.

6. Meko JB, Norton JA. Large cystic/solid thyroid nodules: potential false-negative fine-needle aspiration. Surgery 1995; 118: 9961003. [CrossRef]

7. McCoy KL, Jabbour N, Ogilvie JB, Ohori NP, Carty SE, Yim JH. The incidence of cancer and rate of false-negative cytology in thyroid nodules greater than or equal to $4 \mathrm{~cm}$ in size. Surgery $2007 ; 142$ : 837-844. [CrossRef]

8. Porterfield JR Jr, Grant CS, Dean DS, Thompson GB, Farley DR, Richards ML, et al. Reliability of benign fine needle aspiration cytology of large thyroid nodules. Surgery 2008; 144: 963-968. [CrossRef]

9. Pinchot SN, Al-Wagih H, Schaefer S, Sippel R, Chen H. Accuracy of fine-needle aspiration biopsy for predicting neoplasm or carcinoma in thyroid nodules $4 \mathrm{~cm}$ or larger. Arch Surg 2009; 144: 649-655. [CrossRef]
10. Kuru B, Gulcelik NE, Gulcelik MA, Dincer H The false-negative rate of fine-needle aspiration cytology for diagnosing thyroid carcinoma in thyroid nodules. Langenbecks Arch Surg 2010; 395: 127 132. [CrossRef]

11. Yoon JH, Kwak JY, Moon HJ, Kim MJ, Kim EK. The diagnostic accuracy of ultrasound-guided fine-needle aspiration biopsy and the sonographic differences between benign and malignant thyroid nodules $3 \mathrm{~cm}$ or larger. Thyroid 2011; 21: 993-1000. [CrossRef]

12. Raj MD, Grodski S, Woodruff S, Yeung M, Paul E, Serpell JW Diagnostic lobectomy is not routinely required to exclude malignancy in thyroid nodules greater than four centimetres. ANZ J Surg 2012; 82: 73-77. [CrossRef]

13. Albuja-Cruz MB, Goldfarb M, Gondek SS, Allan BJ, Lew J. Reliability of fine-needle aspiration for thyroid nodules greater than or equal to $4 \mathrm{~cm}$. J Surg Res 2013; 181: 6-10. [CrossRef]

14. Agcaoglu O, Aksakal N, Ozcinar B, Sarici IS, Ercan G, Kucukyilmaz $M$, et al. Factors that affect the false-negative outcomes of fineneedle aspiration biopsy in thyroid nodules. Int J Endocrinol 2013; 2013: 126084. [CrossRef]

15. Wharry LI, McCoy KL, Stang MT, Armstrong MJ, LeBeau SO, Tublin $\mathrm{ME}$, et al. Thyroid nodules $(\geq 4 \mathrm{~cm})$ : can ultrasound and cytology reliably exclude cancer? World J Surg 2014; 38: 614-621. [CrossRef]

16. Yeh MW, Demircan O, Ituarte $\mathrm{P}$ and Clark $\mathrm{OH}$. False-negative fineneedle aspiration cytology results delay treatment and adversely affect outcome in patients with thyroid carcinoma. Thyroid 2004; 14: 207-215. [CrossRef]

17. Braga M, Cavalcanti TC, Collaço LM, Graf H. Efficacy of ultrasoundguided fine-needle aspiration biopsy in the diagnosis of complex thyroid nodules. J Clin Endocrinol Metab 2001; 86: 4089-4091. [CrossRef]

18. Izquierdo R, Arekat MR, Knudson PE, Kartun KF, Khurana K, Kort $\mathrm{K}$, et al. Comparison of palpation-guided versus ultrasoundguided fine-needle aspiration biopsies of thyroid nodules in an outpatient endocrinology practice. Endocr Pract 2006; 12:609.[CrossRef] 